\title{
CONHECIMENTO E APLICAÇÃo do TQM EM ÁREAS dE SUPORTE: O CASO dO DEPARTAMENTO DE LOGísTICA EM UMA INDÚSTRIA AUTOMOTIVA
}

\author{
Christiane Bischof dos Santos ${ }^{1}$, Camilo Henrique Nogueira Martins. ${ }^{2}$ \\ ${ }^{1}$ PUC-PR / Università di Bologna \\ ${ }^{2}$ Robert Bosch Ltda
}

E-mails: christiane.bischof@gmail.com, camilo.martins@br.bosch.com

\section{RESUMO}

O TQM tornou-se uma estratégia importante a partir dos anos 90. Seu foco principal está nas mãos e mentes daqueles que empregam suas técnicas e ferramentas. Também implica que a qualidade deve existir em todos os departamentos e entre todos os níveis hierárquicos. Desde então, muitos estudos foram desenvolvidos para discutir este conceito, no entanto em sua maioria concentram-se em fatores de sucesso e a perspectiva de manufatura ao implementar o TQM. Em geral, não tratam de eventuais discrepâncias que podem potencialmente ocorrer entre departamentos da mesma companhia causados principalmente por diferenças culturais intra-organizacionais. Neste artigo, propõe-se uma avaliação de percepção da qualidade com o objetivo de investigar lacunas em relação ao conceito dos seus métodos, ferramentas, diretrizes e controles. Um questionário foi aplicado a toda a população do departamento de logística (142 colaboradores) em uma indústria automotiva. Por meio de uma análise estatística descritiva aprofundada, obtiveram-se informações importantes que levaram a uma proposta para desenvolvimento de competências customizado para a área de suporte.

\section{INTRODUÇÃO}

Entre as habilidades tácitas de uma empresa está a capacidade de controle da qualidade. Uma vez que o controle da qualidade requer articulações organizacionais complexas, constitui-se em uma vantagem competitiva para as empresas [1]. Algumas pessoas não consideram mais que a capacidade de controle da qualidade seja realmente tácita, uma vez que há uma ampla oferta de manuais e diretrizes referentes aos requisitos da TQM tais como as normas ISO. Alem disso, empresas investem uma grande quantidade de recursos para realizar benchmark em outras empresas com níveis de qualidade superiores tais como Motorola e Toyota e utilizam seus manuais para a melhoria da qualidade dos produtos e serviços da sua companhia. Mesmo assim, algumas falham em atingir tais níveis de qualidade desejados. É aí que se sugere que algumas partes da capacidade de controle da qualidade são ainda predominantemente tácitas e, portanto, podem ser uma fonte de vantagem competitiva sustentável.

Nessa linha, surge nos anos 90, o TQM que se trata de um sistema de gestão com foco no cliente que envolve todos os funcionários na melhoria continua em todos os aspectos da organização. O TQM faz uso de estratégias, dados e comunicação efetiva a fim de integrar os princípios da qualidade na cultura e nas atividades da organização. $\mathrm{O}$ controle da qualidade e 
a conseqüente utilização de seus métodos, ferramentas, diretrizes é uma prática que, segundo as prerrogativas do TQM, deveriam ser de uso comum por todos os departamentos, iniciandose na gestão e disseminando-se para os demais níveis. Há uma vasta literatura que discute e retrata casos de implementação, resultados e fatores de sucesso do TQM em diversas organizações. Fatores culturais e contextuais também são fatores importantes, conforme [15]. No entanto, os estudos em geral tratam da implementação do TQM na empresa como um todo e focam as áreas de manufatura. É necessário avaliar certas defasagens de informações e conhecimento relativo à qualidade que podem afetar particularmente áreas de suporte, em especial a área de logística.

Neste artigo apresentam-se os resultados de um estudo quantitativo realizado em uma indústria do ramo automotivo. A análise descritiva estatística pautou-se nas respostas das 142 pessoas do departamento de logística da empresa. O propósito de utilizar técnicas quantitativas é prover um retrato da situação atual relativa à disseminação do TQM em relação ao uso e conhecimento de métodos, ferramentas, práticas e diretrizes da qualidade. A partir da interpretação e análise criteriosa dos dados, foi possível propor um plano de desenvolvimento de competências adequado a esta área.

Este artigo está organizado em quatro sessões. A primeira examina o significado da qualidade na logística industrial. A segunda descreve a metodologia utilizada no presente estudo. A terceira apresenta e discute os resultados. A última sessão discorre sobre as principais conclusões concernentes à aplicação do TQM no departamento de logística da empresa Beta, apresenta as limitações e sugere alguns encaminhamentos para estudos futuros.

\section{O SIGNIFICADO DA QUALIDADE NA LOGÍSTICA}

A conceituação de logística empresarial se constitui no processo de planejamento, implementação e controle do fluxo eficiente e economicamente eficaz de matérias primas, estoque em processo, produtos acabados e informações relativas desde o ponto de origem até o ponto de consumo, com o propósito de atender às exigências dos clientes [10]. Na mesma linha, Bowersox e Closs [2] afirmam que a logística existe para satisfazer os requisitos do cliente, facilitando a manufatura e as operações de marketing. Dentro do conceito do Supply Chain Management, exerce papel de integração dos fluxos de materiais e informações na Cadeia de Suprimentos. Trata-se efetivamente de um serviço complexo que envolve contato direto com o produto final ao cliente e deve ser cuidadosamente controlado, sejam as funções operacionais ou administrativas. Considerada atualmente como função importante da organização, a logística, negocia valores e disponibiliza o melhor recurso de mobilidade, começando a estabelecer vínculos próprios e complexos, plenamente integrados aos objetivos estratégicos das organizações. Falhas na cadeia logística podem colocar a perder todo o trabalho gerado na cadeia produtiva, negociações e compromissos com o cliente e até mesmo, afetar a reputação da empresa. Holweg e Pils [3] afirmam que compradores normalmente escolhem seus fornecedores de acordo com o preço, seguido pela qualidade e confiabilidade de entrega.

Os constituintes do tripé Qualidade-Custo-Entrega são conectados de forma indissociável, o que é compreensível em um contexto de Just-in-time. De uma maneira geral, se a qualidade entregue pela produção não está conforme, não é possível fornecer e, consequentemente, gera atrasos. Se o fornecimento sofre um atraso, o cliente reclamará pela falta de qualidade no serviço. E, por sua vez, se as exigências do cliente não forem satisfeitas em relação ao horário 
de fornecimento ou ao local de entrega, também se constitui em uma falha de qualidade no serviço. Portanto, conforme salientado em [4], a lucratividade da logística e, consequentemente da cadeia de fornecimento como um todo, está diretamente ligada à gestão não somente dos custos mas também à da qualidade e do desempenho logístico. Não é mais aceitável que os integrantes da função qualidade efetuem controles e auditorias sem levar em conta o impacto de atrasos de fornecimento aos clientes. Por outro lado, não é coerente que os integrantes da função logística negligenciem a qualidade dos produtos, das embalagens e da sua manipulação com o pretexto de ganhar tempo.

Existe uma série de métodos e ferramentas da qualidade, bem como diretrizes e padronizações, que se mostram eficazes para a melhoria dos serviços logísticos mediante a identificação e redução das falhas existentes. Desde ferramentas básicas tais como brainstorming até mais complexas como FMEA (Failure Mode and Effect Analysis), há uma vasta gama de mecanismos que podem auxiliar na prevenção, correção ou melhoria dos processos. E sua aplicação não exclui os processos logísticos. No entanto, é necessário conhecê-los e saber aplicá-los da forma correta. Caso contrário, tornam-se atividades cansativas e dispendiosas, uma vez que tempo e recursos são demandados. Esse resultado constitui-se em uma atividade indesejável mas obrigatória e isto acaba por afetar a motivação dos colaboradores em relação à qualidade. Portanto, o sistema da qualidade deve ser entendido e incentivado por todos os departamentos e níveis hierárquicos.

Com este objetivo, surge nos anos 90, o TQM que se trata de um sistema de gestão com foco no cliente que envolve todos os funcionários na melhoria continua em todos os aspectos da organização. O TQM faz uso de estratégias, dados e comunicação efetiva a fim de integrar os princípios da qualidade na cultura e nas atividades da organização. A American Federal Office of Management [7] define TQM como:

$$
\begin{aligned}
& \text {... uma abordagem organizacional que visa atender às necessidades e expectativas } \\
& \text { dos clientes envolvendo todos os gestores e colaboradores utilizando para isso } \\
& \text { métodos quantitativos para melhorar continuamente os processos, produtos e } \\
& \text { serviços na organização. }
\end{aligned}
$$

É possível depreender desta definição que o TQM não é um mero sistema técnico. É associado à organização propriamente dita, constituindo-se em um sistema social. De acordo com Pike e Barnes [8] as organizações não se tratam somente de sistemas técnicos mas também humanos. Adicionalmente Oakland [9] afirma que TQM é uma tentativa de melhorar a competitividade, a eficiência e a estrutura organizacionais. Com base nestas definições, podem-se identificar dois aspectos importantes que compreendem o TQM: ferramentas e técnicas de gestão bem como conceitos e princípios de gestão.

Segundo [5], a TQM deveria ser rapidamente incorporada e se tornar um "estilo de vida" em muitas organizações. No entanto, Total Quality Management (TQM) não pode se tornar um modo de vida nas organizações de forma imediata. É necessário um tempo a fim de integrar os princípios e as técnicas da qualidade apropriados na cultura da organização. Recursos humanos são igualmente importantes para o sucesso do TQM. Segundo [11], o foco principal da filosofia TQM está nas mãos e mentes daqueles que empregam as ferramentas e técnicas e não nas ferramentas e técnicas propriamente ditas. No entanto, diz-se que a conscientização das pessoas para a qualidade é a proposta central do TQM. Para Crosby [6], um dos autores mais proeminentes nesta área, a conscientização para a qualidade não é somente promover a qualidade dentro da organização, mas também advêm da devida disseminação da informação. $\mathrm{O}$ autor também salienta que a conscientização para a qualidade é extensiva aos gestores que 
devem agir e falar sobre qualidade. Portanto, a conscientização para a qualidade inicia-se na gestão e dissemina-se por toda a organização. No entanto, de acordo com o estudo relatado em [7], esta conscientização pode ser, em algumas vezes, limitada. As informações referentes à qualidade podem ser interpretadas de formas diferentes pelos gestores que trabalham em contextos diferentes e, consequentemente, afeta a percepção dos seus funcionários.

Há uma vasta literatura sobre a aplicação do TQM em processos de manufatura e até mesmo logísticos principalmente relativa à devida implementação dessa abordagem e estudos de caso com o objetivo de analisar os resultados (positivos) advindos da implementação. No entanto, é importante o diagnóstico de um estudo de caso a fim de verificar se a teoria e as prescrições uma vez definidas estão presentes e vivas na organização.

\section{MÉTODO}

A abordagem metodológica caracteriza-se predominantemente como descritiva com a adoção de técnicas quantitativas de análise. A pesquisa descritiva observa, registra, analisa e correlaciona fatos ou fenômenos (variáveis) sem manipulá-los [12]. Também supõe-se que os pesquisadores tenham conhecimento anterior sobre o problema. Foi utilizado para o desenvolvimento desta pesquisa um levantamento de corte transversal. Este método envolve a coleta de informações de uma dada amostra de elementos ou uma população somente uma vez [13].

A avaliação descritiva foi realizada em duas etapas:

1. Mapeamento da "conscientização" para a qualidade, onde será realizada uma verificação item a item em relação às distribuições de freqüência resultantes para o setor como um todo. Esta avaliação serve como resultado a ser comparado com uma "régua" ou um resultado desejado pré-definido.

2. Análises cruzadas (cross-tabs) entre departamentos e principais tópicos relacionados a qualidade, bem como entre níveis hierárquicos e os mesmos tópicos.

3. Elaboração de uma proposta para desenvolvimento de competências na Logística para os diversos níveis hierárquicos adequados ao conhecimento esperado em cada nível.

A população para o presente levantamento é formada pelos funcionários do departamento de logística em uma grande empresa do ramo automotivo. A referida empresa apresenta diversas plantas no Brasil e no exterior, no entanto, para este estudo, somente uma planta foi avaliada. Conforme pode ser verificado, a análise empírica foi realizada utilizando-se um único estudo de caso. Apesar de apresentar limitações significativas em termos de validade [14], abre-se a oportunidade de estudar um fenômeno complexo sob determinadas circunstâncias, evidenciar algumas facetas intangíveis e identificar as relações significativas entre as variáveis e os eventos. De fato, o objetivo deste estudo é empregar um estudo de caso a fim de melhor ilustrar o estado atual do conhecimento e conscientização para a qualidade e um setor de logística em uma empresa reconhecida pela qualidade dos seus produtos.

A indústria do ramo automotivo em questão, este artigo, será chamada Beta a fim de assegurar o devido sigilo das informações. Em uma rápida visão institucional, trata-se de uma empresa alemã que emprega em todo mundo cerca de 300.000 pessoas. O faturamento em 2012 chegou a 52,3 bilhões de euros, sendo 59\% desde valor advindo da divisão automotiva. 
As informações utilizadas neste estudo foram coletadas utilizando-se dados primários .Um questionário foi elaborado com auxílio do software Qualtrics ${ }^{\circledR}$ e o link foi enviado a um facilitador na área que providenciou a resposta de todos os funcionários presentes. De um total de 145 questionários abertos, 142 são considerados válidos. Como a análise proposta neste artigo é puramente descritiva, não implica analise-multivariada portanto, não houve problemas em considerar questionários parcialmente respondidos (presença de missing values). Para analise estatística descritiva, foi utilizado o software IBM-SPSS ®.

Conforme salientado, a metodologia de estudo de caso apresenta limitações significativas, especialmente no que se refere à generalização e validação externa, uma vez que a replicação literal e teórica bem como comparações entre casos não foram empregados. No entanto, devese observar que o propósito deste estudo não é elaborar generalizações a partir de um único caso sob análise. Pelo contrário, o objetivo é estudar e discutir um caso paradigmático que sirva como ilustração útil das variáveis e de suas relações.

\section{RESULTADOS E DISCUSSÃO}

\subsection{Mapeamento da "conscientização para a qualidade"}

Primeiramente, a partir da análise dos resultados gerais para cada uma das questões do questionário, elaborou-se o que denominamos um mapeamento da "conscientização para a qualidade" no departamento de logística em relação ao conhecimento, aplicação, papel das lideranças (gestores), ambiente de trabalho, credibilidade da qualidade e resultados do setor.

$\mathrm{Na}$ figura 1 pode-se verificar um quadro onde é possível visualizar o resultado geral com auxilio de um código de cores (cinza mais intenso, maior percentual de respostas). Está graduação é pura e simplesmente a distribuição de freqüências que poderia também ser representada por histogramas. Quando há um tom mais escuro que os demais, indica a moda da distribuição. Quando não há muita distinção entre as tonalidades, significa que é um item ainda obscuro para o departamento ou que não é entendido por todos os funcionários de maneira uniforme. Na última coluna à direita, intitulada "better when",foi realizada uma avaliação em relação à resposta desejada para cada questão. Nesta faixa dispõe-se o "otput ideal" sendo este estabelecido junto ao representante da qualidade atuante no departamento de Logística e o especialista em métodos e ferramentas da Qualidade.

Adotou-se a escala Likert de 5 pontos (concordo totalmente a discordo totalmente) na ordem direta ou inversa, ou seja, algumas questões são feitas propositalmente de forma negativa a fim de verificar a coerência dos respondentes ao marcar as opções. Como não foi adotada uma resposta dummy para o caso de "não se aplica" ou "não conheço", considerou-se as respostas "3" ou "não concordo, nem discordo" como representativas dessas situações, valendo-se da avaliação individual das questões para a devida interpretação desse resultado.

As questões contidas no questionário estão agrupadas, a princípio, em seis grupos: conhecimento, aplicação das ferramentas, ambiente de trabalho, envolvimento da liderança, credibilidade e resultados. Para os objetivos propostos neste artigo, em que há apenas avaliação descritiva dos dados, não foi realizada a validação dessa escala 
(análise fatorial confirmatória, verificação de consistência interna), não fazendo parte do escopo deste estudo específico.

Q-Methods@Logistic - Descriptive Analysis (Deployment/department)

\begin{tabular}{|c|c|c|c|c|c|c|c|}
\hline & & \multicolumn{5}{|c|}{ Percepções Q-Methods\&Tools } & \multirow[b]{2}{*}{ Ideal * } \\
\hline & & ++ & + & - & -- & $\mathrm{N}$ & \\
\hline \multirow{14}{*}{ 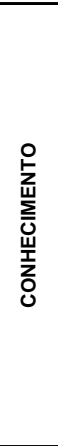 } & |"Conheço os métodos e ferramentas da Qualidade aplicáveis ao meu trabalho." & $17 \%$ & & & $12 \%$ & 138 & $++\leftarrow$ \\
\hline & Avalie seu conhecimento_Pareto & $19 \%$ & $37 \%$ & 17 & $27 \%$ & 131 & $++\leftarrow$ \\
\hline & Avalie seu conhecimento_Estratificação & $5 \%$ & $21 \%:$ & $15 \%$ & 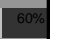 & 131 & $++\leftarrow$ \\
\hline & Avalie seu conhecimento_Ishikawa & $20 \%$ & $32 \%$ & $16 \%$ & $32 \%$ & 131 & $++\leftarrow$ \\
\hline & Avalie seu conhecimento_Carta de Controle & $9 \%$ & $34 \%:$ & $15 \%$ & $42 \%$ & 131 & $++\leftarrow$ \\
\hline & Avalie seu conhecimento_5PQs & $38 \%$ & $49 \%$ & 8\% & $5 \%$ & 131 & $++\leftarrow$ \\
\hline & Em minha área, priorizamos a prevenção dos problemas." & $30 \%$ & $50 \%$ & $8 \%$ & 12\% & 138 & $++\leftarrow$ \\
\hline & A Matriz QA atua na prevenção de possíveis falhas & $22 \%$ & $34 \%$ & $2 \%$ & $41 \%$ & & $\rightarrow--$ \\
\hline & "A Matriz QA é a base para a elaboração de uma boa FMEA." & $20 \%$ & $26 \%$ : & $4 \%$ & $50 \%$ & 137 & $\rightarrow--$ \\
\hline & "Entendo que a Liberação Excepcional não deve ser uma opção frequente, uma vez que trata de desvios d..." & $53 \%$ & $17 \%$ & $3 \%$ & $27 \%$ & 139 & $++\leftarrow$ \\
\hline & O Risk Managament (análise de risco) deve ser utilizado sempre que houver risco de não qualidade par... & $38 \%$ & $21 \%$ & $4 \%$ & $37 \%$ & 140 & $++\leftarrow$ \\
\hline & "Eventualmente, percebo que nossos líderes apresentam divergências entre si em relação à interpretação..." & $19 \%$ & $45 \%$ & $6 \%$ & $29 \%$ & 139 & $\rightarrow--$ \\
\hline & "A FMEA nos auxilia a reduzir os riscos de falhas no processo." & $43 \%$ & $33 \%$ & $3 \%$ & $21 \%$ & 139 & $++\leftarrow$ \\
\hline & "A principal ferramenta da Qualidade para análise de reclamações de CLIENTES é o 8D." & $41 \%$ & $32 \%$ & $4 \%$ & $23 \%$ & 136 & $++\leftarrow$ \\
\hline \multirow{15}{*}{ 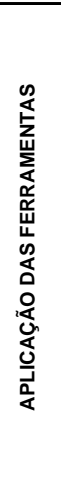 } & "Quando quero avaliar os riscos do processo, opto pela elaboração de uma FMEA." & $37 \%$ & $25 \%$ & $6 \%$ & $32 \%$ & 139 & $++\leftarrow$ \\
\hline & Temos o suporte adequado para aprender e utilizar as ferramentas da qualidade. & $10 \%$ & $32 \%$ & $24 \%$ & $35 \%$ & 139 & $++\leftarrow$ \\
\hline & "Na minha opinião, não precisamos conhecer os métodos da Qualidade pois já há na fábrica um departame..." & $4 \%$ & 9 & 100 & & 140 & $\rightarrow--$ \\
\hline & Na Matriz QA é possível visualizar os maiores riscos do processo. & $4 \%$ & \% & $10 \%$ & & 136 & $++\leftarrow$ \\
\hline & Para nossos problemas de Qualidade no dia a dia, preferimos utilizar uma FSP & $21 \%$ & $44 \%$ & $13 \%$ & $22 \%$ & 136 & (1) \\
\hline & Para nossos problemas de Qualidade no dia a dia, preferimos utilizar uma QAM & $16 \%$ : & $9 \%$ & $39 \%$ & $36 \%$ & 134 & (1) \\
\hline & Para nossos problemas de Qualidade no dia a dia, preferimos utilizar uma PCS & $49 \% "$ & $19 \%$ & $7 \%$ & $25 \%$ & 134 & (1) \\
\hline & Para nossos problemas de Qualidade no dia a dia, preferimos utilizar um Ishikawa & $7 \%$ & $14 \%$ & $28 \%$ & $51 \%$ & 134 & $++\leftarrow$ \\
\hline & Para nossos problemas de Qualidade no dia a dia, preferimos utilizar um 8D & $7 \%$ & $13 \%$ & $13 \%$ & & 134 & $\rightarrow--$ \\
\hline & Está claro para mim quando utilizar um PCS, uma FSP ou um 8D para tratar os problemas de qualidade. & $29 \%$ & $36 \%$ & $10 \%$ & $11 \%$ & 138 & $++\leftarrow$ \\
\hline & Ao emitir uma Desvio, conheço todos os passos e ferramentas necessárias para seu... & $7 \%$ & $23 \%$ & $17 \%$ & $53 \%$ & 139 & $++\leftarrow$ \\
\hline & O Risk Management deve ser sempre emitido pelo departamento de Engenharia. & 19 & $17 \%:$ & & & 139 & $\rightarrow--$ \\
\hline & Sei como divulgar as melhorias que faço em meu processo para outras plantas (Lessons Learned) & $9 \%$ & $24 \%$ & $18 \%$ & $48 \%$ & 139 & $++\leftarrow$ \\
\hline & Quando há um problema, aciono outras plantas para verificar se já não há soluções.." & $3 \%$ & $24 \%$ & $12 \%$ & & 140 & $++\leftarrow$ \\
\hline & $\begin{array}{l}\text { Quando recebemos alguma reclamação do cliente, discutimos e resolvemos o problema em time. } \\
\text { O LPC/LPA é uma ferramenta para confirmação de processo pela liderança. }\end{array}$ & $34 \%$ & $41 \%$ & \%\% & $17 \%$ & $\begin{array}{l}138 \\
137\end{array}$ & $\begin{array}{l}++\leftarrow \\
++\leftarrow\end{array}$ \\
\hline \multirow{5}{*}{ 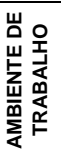 } & Sempre que preciso, encontro os arquivos e ferramentas que preciso para executar a minha atividade. & $25 \%$ & $44 \%$ & 17\%: & & 138 & $++\leftarrow$ \\
\hline & Todos os dias, organizo e limpo meu ambiente de trabalho. & $58 \%$ & $37 \%:$ & $4 \%$ & ।\% & 137 & $++\leftarrow$ \\
\hline & Utilizamos o poka-yoke em algumas estações como ferramenta de controle da Qualidade. & $36 \%$ & $36 \%$ & $6 \%$ & $22 \%$ & 140 & $++\leftarrow$ \\
\hline & "Conheço e sigo todas as instruções que estão disponíveis no meu posto de trabalho." & $44 \%$ & $40 \%$ & $6 \%$ & $11 \%$ & 139 & $++\leftarrow$ \\
\hline & "Meu ambiente de trabalho é limpo e bem organizado." & $39 \%$ & $54 \%$ & $1 \%$ & в\% & 140 & $++\leftarrow$ \\
\hline \multirow{8}{*}{ 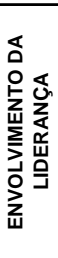 } & Meu líder sabe como direcionar a discussão em grupo para chegarmos à causa raiz. & $29 \%$ & $37 \%$ & $9 \%$ & $24 \%$ & 139 & $++\leftarrow$ \\
\hline & Nossos líderes salientam a importância da utilização dos métodos da Qualidade. & $33 \%$ & $36 \%$ & $12 \%$ & $19 \%$ & 138 & $++\leftarrow$ \\
\hline & Somente tomo conhecimento de auditoria quando sou chamado a participar. & $13 \%$ & $25 \%$ & $29 \%$ & $33 \%$ & 138 & $\rightarrow--$ \\
\hline & "Recebo com antecedência orientações sobre como me preparar para as auditorias." & $39 \%$ & $35 \%:$ & $13 \%$ & $14 \%$ & 140 & $++\leftarrow$ \\
\hline & "Sou orientado pelos meus líderes sobre as diretrizes do grupo (procedimentos, instruçoes) & $1 \%$ & $34 \%$ & $15 \%$ & $40 \%$ & 139 & $++\leftarrow$ \\
\hline & "Quando altero um documento, peço sempre autorização do responsável pelo documento/posto onde se apli..." & $45 \%$ : & $14 \%$ & $5 \%$ & $36 \%$ & 140 & $++\leftarrow$ \\
\hline & "A liderança (em todos os níveis) é bastante participativa nas análises e auditorias em meu processo...." & $\%$ & $32 \%$ & $15 \%$ & $28 \%$ & 139 & $++\leftarrow$ \\
\hline & "Em minha equipe/departamento, os erros que ocorrem são aproveitados para aprender, em conjunto, como..." & $38 \%$ & $38 \%$ & $10 \%$ : & & 140 & $++\leftarrow$ \\
\hline \multirow{7}{*}{ 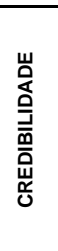 } & Acredito que as ferramentas e métodos da qualidade são úteis para o meu trabalho. & & $28 \%:$ & 0\%: & & 140 & $++\leftarrow$ \\
\hline & Nosso objetivo é sempre solucionar definitivamente os problemas a fim de evitar reocorrências. & & $26 \%$ & $\%$ & & 140 & $++\leftarrow$ \\
\hline & As ferramentas da qualidade nos auxiliam a chegar de forma efetiva às causas-raízes. & $57 \%$ & $35 \%$ & 2\% & & 138 & $++\leftarrow$ \\
\hline & "Na minha opinião, a aplicação dos métodos e ferramentas da qualidade são de responsabilidade do depa..." & $8 \%$ & $22 \%$ & $24 \%$ & & 139 & $\rightarrow--$ \\
\hline & $\begin{array}{l}\text { As ferramentas e métodos da Qualidade são úteis também para aumentar nosso conhecimento em relação a... } \\
\text { "Já temos problemas suficientes e não acho que a utilização de métodos da Qualidade seja prioridade p..." }\end{array}$ & $1 \%$ & $24 \%$ & \%क: & & $\begin{array}{l}140 \\
139\end{array}$ & $\stackrel{++\leftarrow}{\rightarrow--}$ \\
\hline & As ferramentas de qualidade são importantes veículos de aprendizagem em nossa empresa. & & & & & 140 & $++\leftarrow$ \\
\hline & "Confio nos equipamentos de medição e contole disponíveis no meu posto de trabalho." & 23 & $43 \%$ & $7 \%$ & $28 \%$ & 138 & $++\leftarrow$ \\
\hline \multirow{5}{*}{ 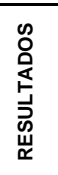 } & Conheço os indicadores da Qualidade da Logística & $23 \%$ & $47 \%:$ & $10 \%$ & $20 \%$ & 136 & $++\leftarrow$ \\
\hline & Tenho informações suficientes sobre a satisfação do cliente final em relação aos produtos e serviços & & & & $36 \%$ & 138 & $++\leftarrow$ \\
\hline & Conheço os custos de desvios causados por nossos fornecedores e sei como cobrá-los & & & & & 140 & $++\leftarrow$ \\
\hline & O cliente deverá receber um retorno pela não-conformidade em no máximo 90 dias... & & & & & & $++\leftarrow$ \\
\hline & A qualidade do serviço na Logística tem melhorado significativamente nos últimos meses. & $27 \%$ & $44 \%$ & & & 136 & $++\leftarrow$ \\
\hline
\end{tabular}

* Avaliação realizada em conjunto com representante da Qualidade na Logística e especialista métodos e ferramentas da Qualidade.

Figura 1: Mapeamento da "conscientização para a qualidade" na Logística

Verifica-se que o conhecimento em relação às ferramentas básicas da qualidade (Pareto, Ishikawa, Estratificação, etc) é bastante limitado e quase não foi possível 
obter uma tendência em relação a uma ou outra ferramenta. Há uma tendência somente para o maior conhecimento no 5 Por quê's, mesmo assim, bastante dispersa. As questões relativas às ferramentas básicas foram as que apresentaram maior quantidade de respostas faltantes. Isto ocorre para todos os níveis, em todos os subdepartamentos (sessões).

Também em relação às ferramentas para auxiliar no tratamento de problemas, verifica-se uma certa confusão entre as ferramentas disponíveis. Não há um consenso sobre qual utilizar e quando utilizar. Verifica-se uma maior tendência para a utilização das ferramentas mais simples, de rápido preenchimento e poucas exigências de formalizações. No entanto, se por um lado a utilização de tais padrões agiliza este processo, por outro se pode incorrer em superficialidade nas análises.

\subsection{Análises cruzadas.}

Nesta etapa foram realizadas análises cruzadas (ou chamadas cross-tabs) entre os diferentes sub-departamentos da logística e os principais tópicos da qualidade (métodos, ferramentas, diretrizes, participação e conhecimento da liderança. Em uma segunda etapa, foram realizadas análises cruzadas entre os níveis hierárquicos e tópicos da qualidade.

A seguir um exemplo de resultado de uma análise cruzada por sub-departamentos da Logística.

\begin{tabular}{|c|c|c|c|c|c|c|c|c|}
\hline & & & "A FMEA & os auxilia a re & duzir os riscos & s de falhas no & processo." & \\
\hline & & & $\begin{array}{c}\text { Concordo } \\
\text { totalmente }\end{array}$ & $\begin{array}{l}\text { Concordo } \\
\text { em parte }\end{array}$ & $\begin{array}{c}\text { concordo } \\
\text { nem }\end{array}$ & \begin{tabular}{|c|} 
Discordo em \\
parte
\end{tabular} & $\begin{array}{c}\text { Discordo } \\
\text { totalmente }\end{array}$ & Total \\
\hline "Escolha o seu & DEP1 & Count & & 3 & 4 & 0 & 0 & 8 \\
\hline departamento." & & \% within "Escolha o seu departamento." & $12,5 \%$ & $37,5 \%$ & $50,0 \%$ & $0,0 \%$ & $0,0 \%$ & $100,0 \%$ \\
\hline & DEP2 & Count & 2 & 2 & 2 & 0 & 0 & 6 \\
\hline & & \% within "Escolha o seu departamento." & $33,3 \%$ & $33,3 \%$ & $33,3 \%$ & $0,0 \%$ & $0,0 \%$ & $100,0 \%$ \\
\hline & DEP3 & Count & 4 & 3 & 0 & 0 & 0 & 7 \\
\hline & & \% within "Escolha o seu departamento." & $57,1 \%$ & $42,9 \%$ & $0,0 \%$ & $0,0 \%$ & $0,0 \%$ & $100,0 \%$ \\
\hline & DEP4 & Count & 2 & 5 & 2 & 0 & 0 & 9 \\
\hline & & \% within "Escolha o seu departamento." & $22,2 \%$ & $55,6 \%$ & $22,2 \%$ & $0,0 \%$ & $0,0 \%$ & $100,0 \%$ \\
\hline & DEP5 & Count & 7 & 1 & 2 & 0 & 0 & 10 \\
\hline & & \% within "Escolha o seu departamento." & $70,0 \%$ & $10,0 \%$ & $20,0 \%$ & $0,0 \%$ & $0,0 \%$ & $100,0 \%$ \\
\hline & DEP6 & Count & 31 & 26 & 15 & 4 & 1 & 77 \\
\hline & & \% within "Escolha o seu departamento." & $40,3 \%$ & $33,8 \%$ & $19,5 \%$ & $5,2 \%$ & $1,3 \%$ & $100,0 \%$ \\
\hline & DEP7 & Count & 2 & 0 & 1 & 0 & 0 & 3 \\
\hline & & \% within "Escolha o seu departamento." & $66,7 \%$ & $0,0 \%$ & $33,3 \%$ & $0,0 \%$ & $0,0 \%$ & $100,0 \%$ \\
\hline & DEP8 & Count & 1 & 0 & 0 & 0 & 0 & 1 \\
\hline & & \% within "Escolha o seu departamento." & $100,0 \%$ & $0,0 \%$ & $0,0 \%$ & $0,0 \%$ & $0,0 \%$ & $100,0 \%$ \\
\hline & DEP9 & Count & 2 & 1 & 0 & 0 & 0 & 3 \\
\hline & & \% within "Escolha o seu departamento." & $66,7 \%$ & $33,3 \%$ & $0,0 \%$ & $0,0 \%$ & $0,0 \%$ & $100,0 \%$ \\
\hline & DEP10 & Count & 1 & 0 & 1 & 0 & 0 & 2 \\
\hline & & \% within "Escolha o seu departamento." & $50,0 \%$ & $0,0 \%$ & $50,0 \%$ & $0,0 \%$ & $0,0 \%$ & $100,0 \%$ \\
\hline & DEP11 & Count & 2 & 1 & 1 & 0 & 0 & 4 \\
\hline & & \% within "Escolha o seu departamento." & $50,0 \%$ & $25,0 \%$ & $25,0 \%$ & $0,0 \%$ & $0,0 \%$ & $100,0 \%$ \\
\hline & DEP12 & Count & 5 & 2 & 0 & 0 & 0 & 7 \\
\hline & & \% within "Escolha o seu departamento." & $71,4 \%$ & $28,6 \%$ & $0,0 \%$ & $0,0 \%$ & $0,0 \%$ & $100,0 \%$ \\
\hline & DEP13 & Count & 0 & 2 & 0 & 0 & 0 & 2 \\
\hline & & \% within "Escolha o seu departamento." & $0,0 \%$ & $100,0 \%$ & $0,0 \%$ & $0,0 \%$ & $0,0 \%$ & $100,0 \%$ \\
\hline Total & & Count & 60 & 46 & 28 & 4 & 1 & 139 \\
\hline & & \% within "Escolha o seu departamento." & $43,2 \%$ & $33,1 \%$ & $20,1 \%$ & $2,9 \%$ & ,7\% & $100,0 \%$ \\
\hline
\end{tabular}

Figura 2 : Cross-tabs departamentos x conhecimento métodos e ferramentas da Qualidade 
A figura 3 apresenta um exemplo de análise cruzada entre níveis hierárquicos.

"Marque a opção que se aplica a sua função atual:" * "Nosso objetivo é sempre solucionar definitivamente os problemas a fim de evitar

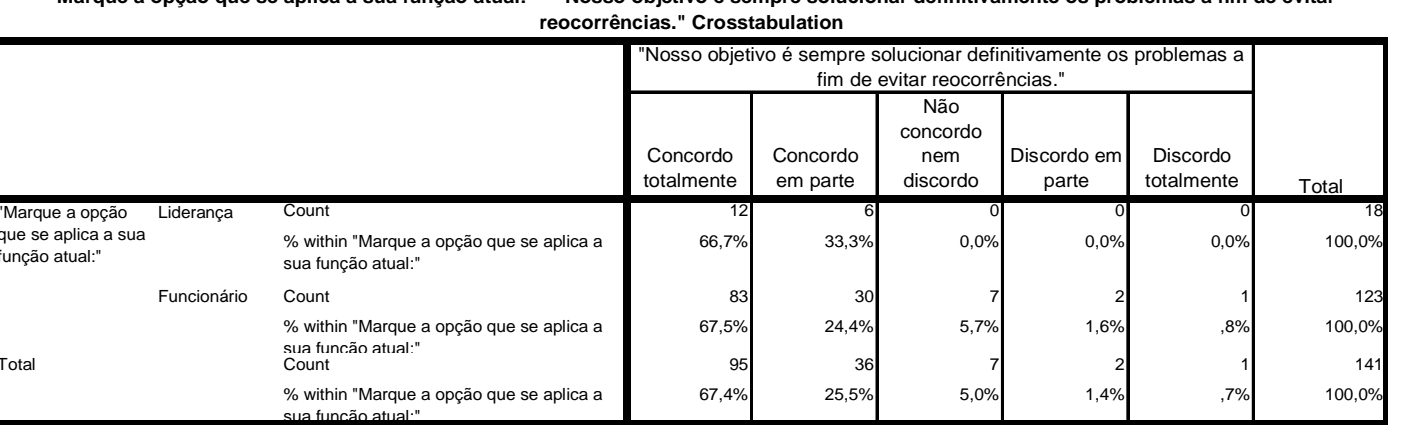

Figura 3: Cross-tabs nível hierárquico x métodos e ferramentas da Qualidade

Verifica-se pelas análises cruzadas que há algumas divergências entre as percepções para os diversos departamentos. Em princípio não haveria problemas em verificar tais diferenças inter-departamentais, uma vez que a qualificação e informações acerca das ferramentas da qualidade pode variar em função da competência/cargo. Para isso propõe-se a matriz de desenvolvimento de competências que procura customizar o grau de conhecimento necessário para cada função/ nível hierárquico.

A partir dessas avaliações entre funcionários e lideranças, foi possível verificar que para alguns temas da qualidade há divergências de opiniões entre funcionários e liderança, o que indica, para alguns casos, um viés na transmissão do conhecimento e no alinhamento das informações. Outra verificação importante é referente aos indicadores de desempenho do setor. Verifica-se que a informação sobre a satisfação dos clientes quanto ao serviço logístico está clara para os líderes. Para os funcionários isto varia bastante e a maior parte encontra-se sem saber exatamente se concorda ou discorda desta afirmação.

A partir da pesquisa realizada e análise estatística dos dados, pode-se inferir que o departamento de Logística na empresa Beta:

1. Acredita na utilidade das ferramentas da qualidade (credibilidade)

2. Por outro lado, contatou-se que há divergência entre interpretações e compreensão dos métodos apresentadas pela liderança do setor. Isto pode levar, como conseqüência, à utilização incorreta das ferramentas, métodos e diretrizes da qualidade.

3. A maior parte dos funcionários desconhecem os documentos da qualidade da empresa.

4. A maior parte dos respondentes conhecem os métodos e ferramentas de uso obrigatório na empresa (tais como FMEA, 8D), no entanto, carecem de conhecimento das ferramentas básicas. Como exemplo, pode-se dizer que um funcionário sabe o que é um Risk Assessment (uma metodologia bastante complexa) mas não sabe o que é um Pareto. Ou ainda pior: pode ficar na dúvida entre fazer um 8D (método para solução de problemas) e um Ishikawa, o que não faz sentido, já que um engloba o outro. 
3.3 Proposta para o desenvolvimento de competências na Logística

Na figura 4 é possível ver o resultado das análises e discussões referentes ao perfil de competências desejado para o departamento de logística.

Foram definidos 6 níveis de competência, não sendo estes diretamente relacionados aos níveis hierárquicos.Cabe ao departamento de Logística definir o publico alvo para cada nível de competência. É necessário ponderar, todavia, que a complexidade de análise em relação à aplicação das ferramentas, métodos e diretrizes da qualidade eleva-se a medida que os níveis de competência sobem. Os níveis foram numerados de 0 a 5 . Apresenta-se a seguir, um breve resumo da proposta elaborada.

Nível 0: "Básico" - compreende conhecimento básico e utilização do 5S, PokaYokes e Diagrama de Ishikawa (participação em times de solução de problemas).Segue a documentação da qualidade disponível em seu posto de trabalho.

Nível 1: "Básico +" - compreende conhecimento básico e utilização do 5S, Pokayokes, Ishikawa e conhecimento rudimentar de outras ferramentas básicas tais como estratificação e Brainstorming. Suporta times de solução ou prevenção de problemas prestando informações técnicas necessárias. Segue a documentação da qualidade disponível em seu posto de trabalho e, quando necessário, requisita e auxilia na sua revisão.

Nível 2: Intermediário: conhecimento já incorporado quanto ao uso de $5 \mathrm{~S}$ e Pokayokes. Possui certa experiência com ferramentas da qualidade e incentiva seu uso para avaliação. Procura e incentiva a disseminação das lições aprendidas com as demais plantas do grupo. Conhece a documentação da empresa e seus diversos níveis (planta, divisão, corporativa). Sabe elaborar um documento conforme requisitos locais. Participa efetivamente dos times de solução de problemas e análises de risco preventivas Incentiva a utilização de ferramentas básicas da qualidade para melhor compreensão das falhas e definição da causa raiz.

Nível 3: Avançado: é responsável pela implementação e controle do 5S e Poka-yokes no(s) posto(s) de sua responsabilidade. É capaz de decidir qual ferramenta da qualidade é a mais adequada para chegar a causa raiz dos problemas. Também é capaz de ministrar curtos treinamentos aos funcionários do setor sobre a utilização de ferramentas básicas da qualidade. Procura e incentiva a disseminação das lições aprendidas com as demais plantas do grupo. Conhece a documentação da empresa e seus diversos níveis (planta, divisão, corporativa). Sabe elaborar um documento conforme requisitos locais. É capaz de moderar ou liderar times para solução de problemas, análise de riscos.

Nível 4: Lideranças- foco na análise critica dos resultados: é capaz de identificar rapidamente desvios ao 5S ou implementação de poka-yokes. É capaz de decidir qual ferramenta da qualidade é a mais adequada para chegar a causa raiz dos problemas. Recebe informações sobre lições aprendidas em demais plantas do grupo e incentiva a disseminação das lições aprendidas internas. Conhece os documentos aplicáveis ao departamento e sabe como avaliar se documentos elaborados internamente estão de 
acordo com as diretrizes da qualidade. Avalia os resultados de análise dos times de solução de problemas e análise de riscos em relação a sua coerência e profundidade. Tem a responsabilidade de avaliar e assegurar que ações de melhoria ou prevenção propostas apresentem um prazo factível e sejam efetivas.

Nível 5: coordenador da qualidade do departamento: é capaz de identificar rapidamente desvios ao 5S. Participa de avaliações e auditorias realizados pelo departamento da qualidade ou empresas externas no setor. Sabe como avaliar a causa raiz e sugerir as ferramentas e métodos da qualidade mais adequados. Conhece e sabe explicar a estrutura de documentos e diretrizes da Qualidade na empresa. Sabe também como orientar os demais funcionários na elaboração de novos documentos. É capaz de ministrar treinamentos curtos sobre métodos e ferramentas da Qualidade. Eventualmente, pode ser requisitado pela liderança para apoiar em determinadas análises em questões da qualidade.

Como pode-se verificar, enquanto o nível "0" somente implica o conhecimento superficial de poucas ferramentas, a partir do nível "4", indicado para as lideranças, foca-se a análise critica da utilização dos métodos, ferramentas e diretrizes bem como seus resultados e inter-relações.

O nível " 5 ", ou de coordenador na área deveria, em principio, ser atribuído a somente uma ou duas pessoas no departamento, uma vez que define um nível de conhecimento aprofundado. É uma decisão do departamento em adotar este nível de competência ou não, salientando que não há necessidade de se ter um expert da qualidade no setor se os demais níveis forem devidamente aplicados. Em especial, uma liderança com o nível 4 sugerido é um objetivo que deve ser perseguido.

Tendo em vista que a liderança da Logística da empresa Beta sofreu alterações importantes nos últimos anos - segundo informação dos próprios funcionários da empresa- entende-se que é fundamental um trabalho de nivelamento top-down.

Conforme as prerrogativas do TQM, já salientadas inicialmente, a gestão tem um importante papel na incorporação desta filosofia. Portanto, treinamentos, e utilização extensiva e exaustiva de ferramentas e documentos da qualidade poderão resultar em um investimento em vão caso não se almeje efetivamente adotar o TQM como um "estilo de vida" conforme preconizado em [5]. 


\begin{tabular}{|c|c|c|c|c|c|c|c|c|}
\hline $5 S$ & Poka-Yoke & Q-Basic Tools & Lessons Learned & Q-Guidelines & $8 \mathrm{D}+$ Problem solving tools & FMEA & Quality matrix & $3 \times 5 \times$ Why \\
\hline \multicolumn{9}{|c|}{ Level 5 - Department Q-Coordinator } \\
\hline $\begin{array}{l}\text { is able to quickly } \\
\text { identify } 5 \text { S deviations. }\end{array}$ & 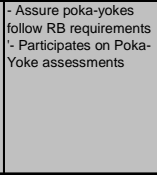 & 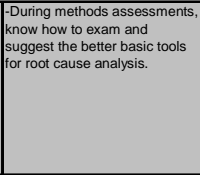 & 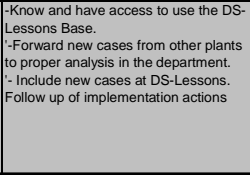 & 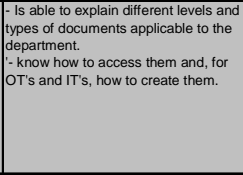 & 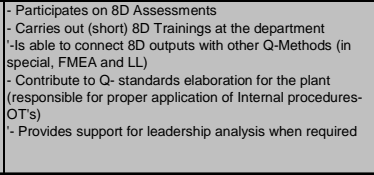 & 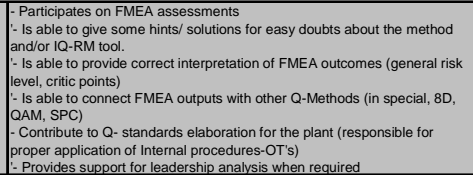 & 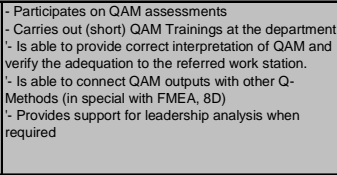 & 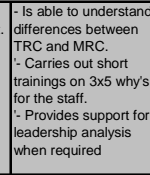 \\
\hline
\end{tabular}

Level 4 - Leadership - focus on critical analysis of the results

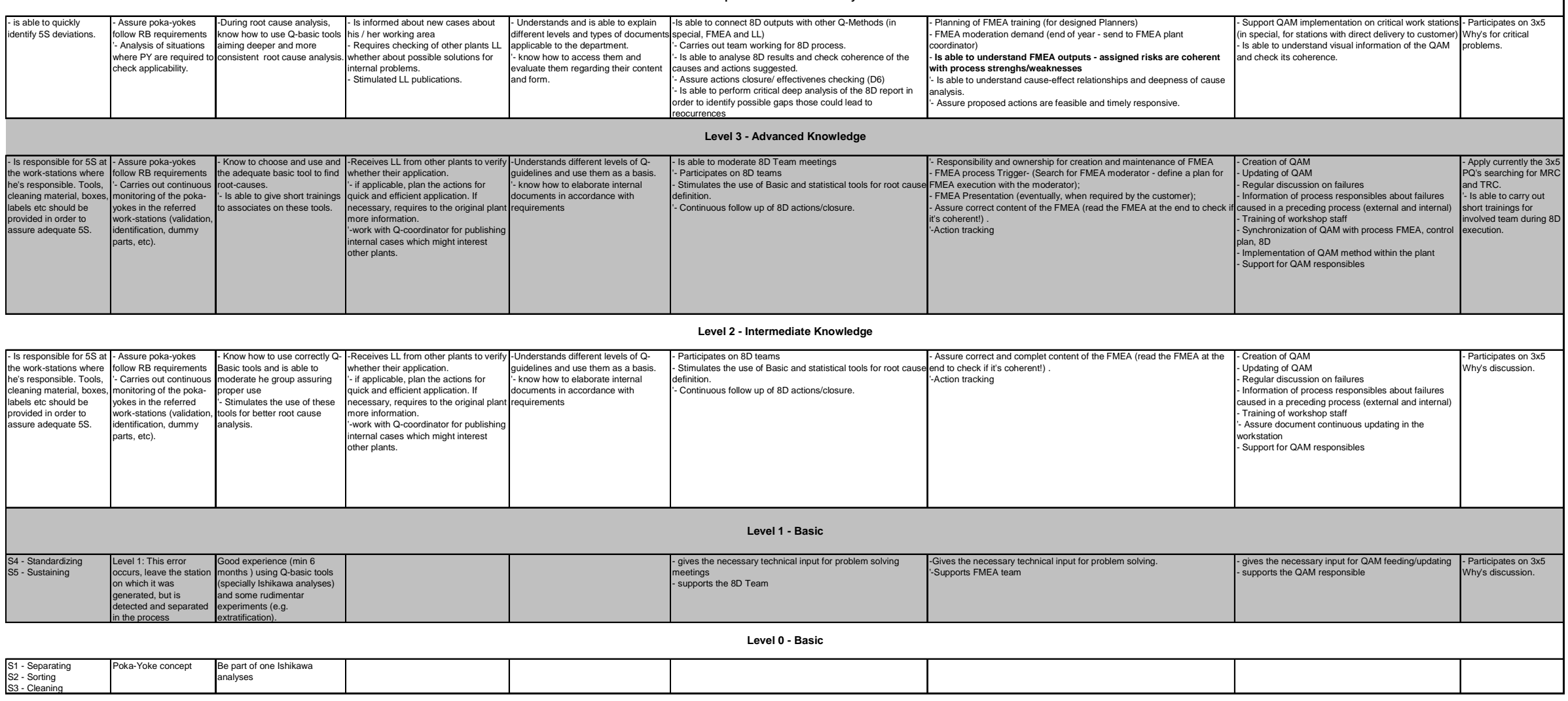

Figura 4: Proposta matriz de desenvolvimento de competências do departamento de Logística da empresa Beta. 


\section{CONCLUSÃO}

O presente artigo apresenta uma avaliação da implementação e da aplicação da filosofia do TQM em uma área suporte, no caso Logística, em uma industria do setor automotivo. Foi realizada uma pesquisa de cunho quantitativo utilizando para isso os dados primários provenientes de aplicação de um questionário a todos os funcionários da área de logística. Um total de 142 respostas válidas foi obtido. O objetivo do questionário foi avaliar o grau de percepção e conscientização para a qualidade.

Com estes resultados, foi possível realizar uma avaliação estatística descritiva e com isso, obter um retrato atual do grau de conscientização para a qualidade. Esta avaliação foi compilada em um quadro que foi denominado pelos autores como "mapeamento da conscientização para a qualidade". Esta representação visa apresentar os dados da pesquisa de forma compilada e de fácil interpretação pelos gestores e demais envolvidos.

A estatística descritiva também possibilita a realização de análises cruzadas, onde é possível avaliar os resultados por sub-departamento ou nível hierárquico. Estas avaliações são importantes para determinar o grau de uniformidade relacionado ao conhecimento e conscientização para a qualidade.

Por fim, com base nesse aprendizado advindo da análise dos dados coletados, propôs-se uma matriz de desenvolvimento de competências estabelecendo níveis de conhecimento e análise necessários a serem perseguidos pelo departamento como um todo a fim de promover o TQM como um "estilo de vida" tal como sugere Oakland [5]. Os resultados também indicam que é necessário reforçar conhecimentos básicos da qualidade para que se forme uma base sólida para a devida utilização e compreensão de métodos e ferramentas mais complexos. Outra conclusão importante é o papel das lideranças (gestores) nesse processo. Uma disseminação e agregação de conhecimento da Qualidade deve ser um processo top-down e não restrito a poucas pessoas designadas. $\mathrm{O}$ fato da empresa Beta ter apresentado algumas alterações no quadro de gestores nos últimos anos é um indicio de que o desenvolvimento do TQM como um "estilo de vida" no departamento dificilmente pode ocorrer tendo em vista que se trata de um processo de longo prazo e somente consolida-se com agregação de experiência e conhecimento.

Dentre as limitações do estudo, está o estudo de um único caso, conforme já salientado na sessão 2, o que implica a impossibilidade de generalização. Outra limitação a se considerada é o fato de todos os funcionários responderem ao questionário no ambiente do trabalho, com poucos computadores disponibilizados para esse fim. Para acessar o link do Qualtrics é necessário acesso à internet e nem todos os funcionários da empresa possuem este acesso.

Estudos quantitativos e qualitativos devem ser aplicados em outros setores da indústria, visando investigar a uniformidade de implementação e compreensão do TQM nas diferentes áreas que estão diretamente envolvidas ou prestam suporte à cadeia de agregação de valor. Estudos recentes foram realizados com o objetivo de verificar como abordagens gerenciais e relações sociais podem afetar a implementação e internalização do TQM na empresa, tais como [15] e [16]. A pesquisa considerando diferenças entre contextos e culturas organizacionais também deve ser encorajada. 


\section{REFERÊNCIAS}

[1] WINTER, S.G. Knowledge and competence as strategic assets in TEECE, D.J. The Competitive Challenge, Ballinger: Cambridge, pp. 159-184, 1987.

[2] BOWERSOX, D.J.; CLOSS, D.J. Logistical management: the integrated supply chain process, $3^{\text {a }}$. Ed.; New York: McGraw-Hill, 1996.

[3] HOLWEG, M.; PIL, P.K. Flexibility first: keeping the automotive supply chain responsive through build-to-order. Industrial Engineer, vol 37 (6), p. 46, Jun/2005.

[4] HOHMANN, Christian. La convergence qualité/logistique: un potential d'économies intéressant. Qualité Références , p. 5-6, Jul/2006.

[5] OAKLAND, J. Total quality management. Oxford, UK: Heinemann, 1989.

[6] CROSBY, B. P. Quality without tears: The art of hassle-free management. New York: McGraw-Hill, 1984.

[7] MORGAN, C; MURGATROYD, S. Total quality management in the public sector. Buckingham, UK: Open University Press, 1997.

[8] PIKE, J; BARNES, R. TQM in Action: A practical approach to continuous performance improvement. London: Chapman and Hall; 1996.

[9] OAKLAND, J. Total quality management: The route to improving performance. London: Butterworth Heinemann, 1993.

[10] BALlOU, Ronald. Gerenciamento da Cadeia de Suprimentos: Logistica Empresarial, 5a ed.; Bookman: Porto Alegre, 2006.

[11] ANTONY, J.. LEUNG, K.; KNOWLES,G.; GOSH, S.. Critical success factors of TQM implementation. International Journal of Quality \& Reliability Management, Vol. 19 (5), pp. 551-566, 2002.

[12] CERVO, A.L., BERVIAN, P.A. Metodologia científica, $4^{a}$ Ed., São Paulo: Makron Books, 1996.

[13] MALHOTRA, N.K. Pesquisa de Marketing: uma orientação aplicada, $3^{\text {a }}$. Ed., Porto Alegre: Bookmann, 2001.

[14] YIN, R.K. Estudo de Caso: Planejamento e Métodos, 2.ed. -Porto Alegre : Bookman, 2001

[15] WILKINSON, A.; WILLMOTT, H. (1995). Making quality critical: new perspectives of organizational change, London: Routledge, pp. 1-32., 1995. 
[16] PSYCHOGIOS, A.G.; PRIPORAS, C.V.; Understanding Total Quality Management in Context: Quantitative Research on Manager's Awarenenss of TQM Aspects in the Greek Service Industry, The Qualitative Report, Vol. 12 (1), p. 40-66, Mar/2007. 